Tohoku J. Exp. Med., 2005, 206, 195-202

\title{
Strategies for Improving Pediatric Services in Japan
}

\author{
Hansheng Ding, ${ }^{1,2}$ Nobuo Koinuma, ${ }^{1}$ Michiya Ito ${ }^{1}$ and Toshinito Nakamura ${ }^{1}$ \\ ${ }^{I}$ Department of Health Administration and Policy, Tohoku University, Graduate \\ School of Medicine, Sendai, Japan, and \\ ${ }^{2}$ Aetna School of Management, Shanghai Jiao Tong University, Shanghai, China
}

\begin{abstract}
Ding, H., Koinuma, N., Ito, N. and Nakamura, T. Strategies for Improving Pediatric Services in Japan. Tohoku J. Exp. Med., 2005, 206 (3), 195-202 — The shortage of pediatricians and emergency medical care for children is an issue of great concern in Japan. This study attempts to identify the problems in children's medical care and their causes. With multiple secondary data sources, we found that over $80 \%$ of outpatient pediatric services were provided by clinics, that over $95 \%$ of clinics were closed on holidays, Sunday, and Saturday night, that among the children's illnesses respiratory ailments were dominant and were generally acute and required immediate treatment or consultation, and that the revenue rates from providing services for children were lower than those for adults. That fewer clinics are open on Saturday night, Sunday and holidays, and workday evenings may be the main reason why it is difficult for children to find pediatric services outside of normal working hours. Lower revenue rates may be one of the key reasons why the number and rate of clinics and hospitals providing pediatric services continue to decline, and fewer physicians are willing to provide services for children. The findings in this research would provide important information of multiple dimensions for the governments to make efforts to improve pediatric services in Japan. Our proposition is to prompt pediatric specialists and internists who can treat pediatric cases in clinics to provide pediatric service systematically and alternatively at night, and to adjust the fee-for-service scales of pediatric services. - pediatricians; health manpower; health services accessibility; fewer children; health policy
\end{abstract}

(C) 2005 Tohoku University Medical Press

The shortage of pediatricians and emergency medical care for children is a great concern in Japan. On December 14, 2001, Mrs. Iwanaga gave a petition to the local government to improve emergency pediatric services that was signed by about 11,000 individuals (Anonymous 2001a). Asahi Shimbun reported on the necessity of suitable manpower for emergency service for children on July 16, 2001, on the suicide of a pediatrician on September 18, 2001, and on the status quo of children's emergency visits on September 20, 2001 (Anonymous 2001b, c, d). Yomiuri Shimbun reported on the higher work pressure of pediatricians on June 20 - 24, 2001, and on March 2, 2004. Additionally, Japan Broadcasting Corporation discussed the serious situation of the inadequate number of pediatricians for emergency services in "Close-up nowadays" on January 7, 2003. Also, from January to June, 2002, Kahoku Shimpo reported on this issue in a series titled

Received March 2, 2005; revision accepted for publication April 11, 2005.

Correspondence: Hansheng Ding, Department of Health Administration and Policy, Tohoku University, Grad-

uate School of Medicine, 2-1, Seiryomachi, Aoba-ku, Sendai 980-8575, Japan.

e-mail: dinghansheng@mail.tains.tohoku.ac.jp, dinghansheng@ hotmail.com 
"The future of children, from the field of medical services for children." On July 17, 2001, Japan Pediatric Society, Japan Society of Child Care, and Japan Pediatric Association gave their suggestions to the Ministry of Health, Labour and Welfare on how to maintain the emergency medical system for children. In order to overcome the situation, a three-year research project, led by Professor Kamoshita, was conducted from 2002.

By collective efforts, much progress was made to provide medical service for children. However, various improvements continue to be needed. In this paper, we try to clarify the problems in children medical care, to determine the reasons for these problems, and provide suggestions for improving the situation.

\section{Data And Method}

Our data set is a compilation from multiple secondary sources, which were published openly. The data of the children's population in 2002 came from "Population Trend, Japan and the World" (National Institute of Population and Social Security Research 2002). Numbers of medical personnel providing pediatric services in 2002 were obtained from "Survey on physicians, dentists, and pharmacists" (Statistics and Information Department, Minister's Secretariat, Ministry of Health, Labour and Welfare 2002a). The figures for the national medical expenditures in 2002 came from the book "National medical expenditures" (Statistics and Information Department, Minister's Secretariat, Ministry of Health, Labour and Welfare 2002b). The patient survey was conducted by Ministry of Health, Labour and Welfare, Japan, in order to grasp information about patients' use of medical institutions and their diseases (Statistics and Information Department, Minister's Secretariat, Ministry of Health, Labour and Welfare 2002c). The numbers of inpatients and outpatients and their disease classifications in 2002 were obtained from "Patient Survey." Revenue information in 2002 was taken from "Reimbursement Survey for Social Health Services" (Statistics and Information Department, Minister's Secretariat, Ministry of Health, Labour and Welfare 2002d). The numbers of hospitals and clinics, and their service time in 2002 were from "Medical Facility Survey" (Statistics and Information Department, Minister's Secretariat, Ministry of Health, Labour and Welfare 2002e). Some data were from the homepage of
Ministry of Health, Labour and Welfare at http:// wwwdbtk.mhlw.go.jp/toukei/cgi/j_kensaku. The child populations in 1982 and 1984 were estimated based on numbers of children in 1980 and 1985, which were published by the Ministry of Internal Affairs and Communications, Statistics Bureau. All other data from 1982 to 2000 at two-year intervals were collected from the same sources in the corresponding years.

In this analysis, children were defined as those under 15 years, and pediatricians were classified into two categories according to the character of their medical practice. One category refers to those who provide medical services primarily for children (abbreviated as pediatric specialist). The other refers to those, who provide medical services for children, but not primarily (abbreviated as pediatricians internist). The pediatrician-to-child population ratio per 100,000 children (PCPR) was used as a measure of accessibility (Randolph and Pathman 2001).

In this paper, large cities are all of the 13 designated cities whose populations are each over one million. They were the wards of Tokyo, Sapporo-shi, Sendai-shi, Chiba-shi, Yokohama-shi, Kawasaki-shi, Nagoya-shi, Kyoto-shi, Osaka-shi, Kobe-shi, Hiroshima-shi, Kitakyushu-shi, and Fukuoka-shi. Core cities were all of the 12 cities defined by the Japanese government in 1996 whose populations were each between 300,000 and 500,000. They were Utsunomiya-shi, Niigata-shi, Toyama-shi, Kanazawa-shi, Gifu-shi, Shizuoka-shi, Hamamatsu-shi, Sakai-shi, Himeji-shi, Okayama-shi, Kumamoto-shi, and Kagoshima-shi.

\section{RESUlts}

Number of children and pediatricians, and medical expenditures

In the recent two decades, the numbers of children and internist pediatricians have declined sharply. The number of children decreased $32.7 \%$, from 26.9 million in 1982 to 18.1 million in 2002. The averaged annual rate of decrease was about $2.0 \%$ for children. The number of pediatric specialists increased $79.4 \%$ from 8,071 in 1982 to 14,481 in 2002, and pediatricians internist decreased $31.7 \%$, from 26,671 to 18,225 (Fig. 1). In $2002,41.8 \%$ of the total 14,481 pediatric specialists were in clinics, while $93.5 \%$ of the total 18,225 pediatricians internist were in clinics. The average age for all pediatricians was 54.5 in 2002 , 


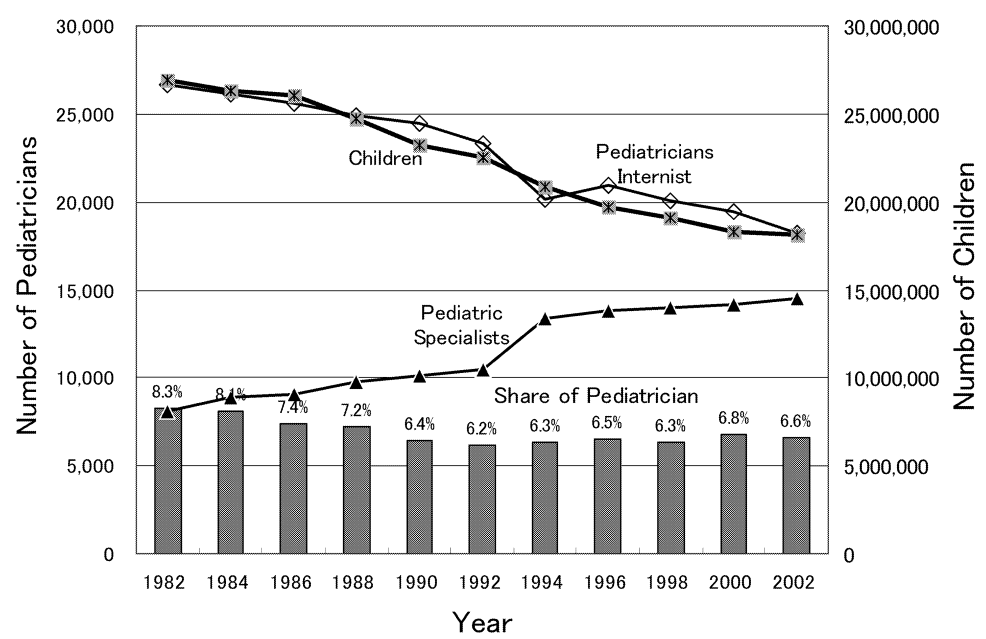

Fig. 1. Number of children, pediatricians, and medical expenditure share for pediatricians.

47.6 for pediatric specialists, and 60.0 for pediatricians internist. There was no great change in the average age of pediatricians during these years. Classified by patient age, the medical expenditures for pediatric services were analyzed. The medical expenditure share for all pediatric services had declined $1.7 \%$, from $8.3 \%$ to $6.6 \%$ (Fig. 1).

\section{PCPR in different areas}

The PCPRs basically differed among the large cities, core cities, and other areas. $20 \%$ of children, in the large cities, had the highest PCPRs in total, and $75 \%$ of children, in the other areas, had the lowest PCPRs in total. There was no large increase or reduction in total PCPRs dur- ing the period from 1996 to 2000 (Table 1).

Services for children by hospitals and clinics

Most of the new outpatients were treated in clinics, while most of the new inpatients were treated in hospitals. Clinics provided $82.6 \%$ of first consultations for those under 15 years old, and $68.7 \%$ for those 15 years and older. Hospitals provided about $90 \%$ of services for new inpatients, both for children and adults.

\section{Clinics providing pediatric services}

According to the medical facility survey, on October 1, 2004 there were 94,819 clinics, of which $27.3 \%$ provided medical services for children. $55.2 \%$ of clinics were established by indi-

TABLE 1. Accessibility to pediatricians in different areas

\begin{tabular}{lcccc}
\hline \multirow{2}{*}{ Area } & Year & \multicolumn{3}{c}{ PCPR $^{*}$} \\
\cline { 3 - 5 } & 1996 & $\begin{array}{c}\text { Pediatric } \\
\text { specialists }\end{array}$ & $\begin{array}{c}\text { Pediatricians } \\
\text { internist }\end{array}$ & Total \\
\hline Large cities & 2000 & 104 & 137 & 242 \\
& 1996 & 96 & 130 & 242 \\
Core cities & 2000 & 104 & 97 & 193 \\
& 1996 & 59 & 99 & 202 \\
The other areas & 2000 & 67 & 99 & 159 \\
& & & 100 & 167 \\
\hline
\end{tabular}

${ }^{*} \mathrm{PCPR}=($ Number of pediatricians $) /($ Number of children $) * 100,000$ 


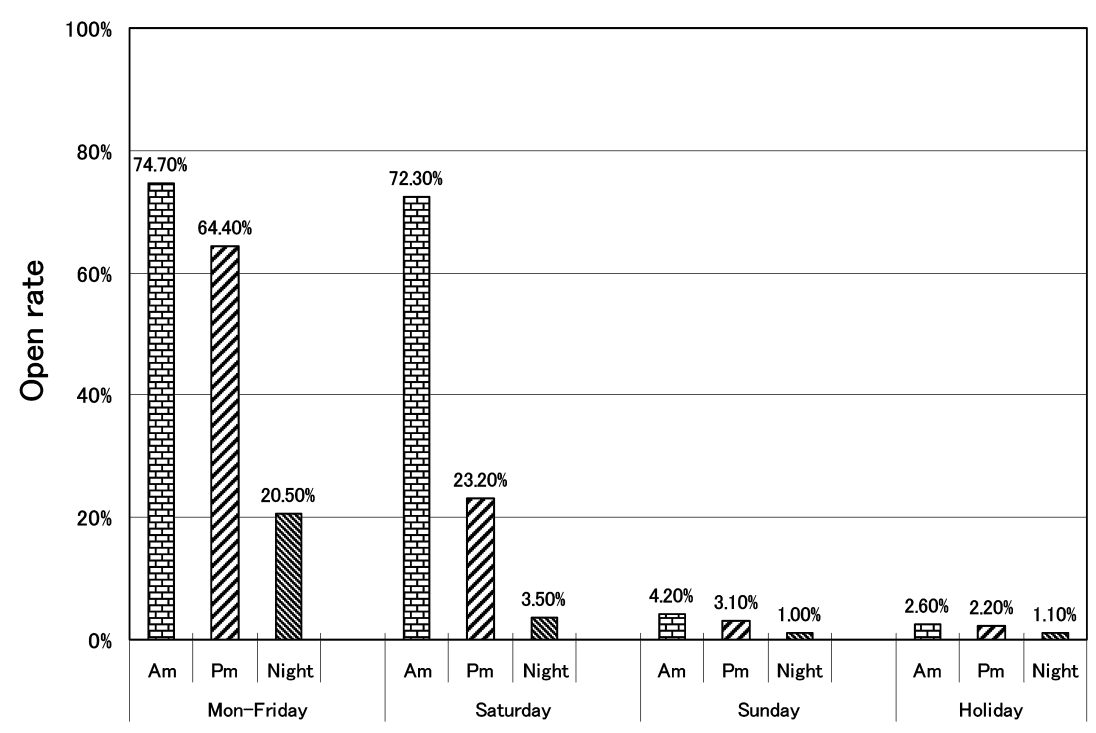

Fig. 2. Open rates of clinics according to the day of the week and time of day.

viduals, and $28.6 \%$ by medical organizations. $29.6 \%$ of the clinics established by individuals provided medical services for children, and $30.7 \%$ of clinics established by medical organizations provided services for children. Of the 4,186 government-owned clinics, one third provided services for children. Between clinics with or without beds, there was no great difference in the rates of providing services for children.

\section{Service time by clinics}

The open rates of clinics vary greatly according to the day of the week and the time of day. The open rates of clinics were higher in the morning and afternoon of workdays, and on Saturday morning. On workday nights and Saturday afternoons, the open rates declined to about $20 \%$. On Sunday and holidays, the open rates were lower than $5 \%$ throughout the day.

\section{Disease pattern}

There were 232.6 thousand first consultation outpatients under 15 years old, and 622.6 thousand outpatients 15 years and older in all hospitals and clinics per day in October 2004. For outpatients, the most common diseases were those of the respiratory system, $57.2 \%$ for children and $22.3 \%$ for adults. For inpatients, their diseases showed similar patterns to those of outpatients.

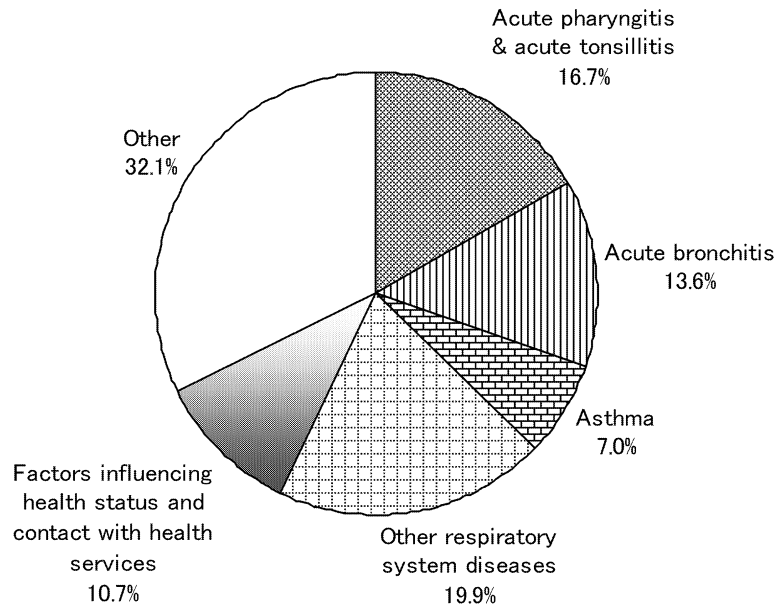

Fig. 3. Disease patterns of pediatric outpatient services.

Generally, most illnesses in children, for example, acute pharyngitis and acute tonsillitis, acute bronchitis, and asthma, are acute and require immediate treatment.

\section{Revenue from services}

The physicians' averaged revenues from outpatients per day decreased generally with increasing age of outpatients. An outpatient visit of a child would bring 5,000 to 6,000 yen of revenue to physicians, $75.9 \%$ of the average revenue for all patients. The outpatient re-visit time for chil- 
TABLE 2. Daily revenue from and use frequency of patients by age

\begin{tabular}{rccccccr}
\hline & \multicolumn{3}{c}{ Outpatient } & & \multicolumn{3}{c}{ Inpatient } \\
\cline { 2 - 3 } \cline { 6 - 7 } Age group & $\begin{array}{c}\text { Total } \\
\text { (Yen/day) }\end{array}$ & $\begin{array}{c}\text { Drug } \\
\text { (Yen/day) }\end{array}$ & $\begin{array}{c}\text { Re-visit } \\
\text { time }\end{array}$ & & $\begin{array}{c}\text { Total } \\
\text { (Yen/day) }\end{array}$ & $\begin{array}{c}\text { Drug } \\
\text { (Yen/day) }\end{array}$ & $\begin{array}{c}\text { Length } \\
\text { of stay }\end{array}$ \\
\hline $0-4$ & 5,022 & 682 & 1.7 & & 33,374 & 1,838 & 6.2 \\
$5-9$ & 5,171 & 1,100 & 1.6 & & 30,197 & 2,824 & 7.4 \\
$10-14$ & 6,018 & 1,685 & 1.5 & & 28,561 & 2,761 & 10.7 \\
$15-19$ & 6,133 & 1,384 & 1.5 & & 27,223 & 3,048 & 10.0 \\
$20-24$ & 6,394 & 1,312 & 1.5 & & 27,088 & 2,945 & 9.2 \\
$25-29$ & 6,118 & 1,331 & 1.5 & & 25,780 & 2,400 & 8.7 \\
$30-34$ & 7,100 & 2,298 & 1.7 & & 25,965 & 2,603 & 9.5 \\
$35-39$ & 6,765 & 1,693 & 1.7 & & 21,926 & 2,195 & 12.7 \\
$40-44$ & 6,770 & 1,947 & 1.8 & & 23,216 & 2,655 & 13.6 \\
$45-49$ & 7,604 & 2,259 & 1.8 & & 23,214 & 2,781 & 14.5 \\
$50-54$ & 7,523 & 2,332 & 1.9 & & 23,722 & 3,218 & 15.4 \\
$55-59$ & 7,221 & 2,407 & 2.0 & & 23,885 & 3,078 & 15.4 \\
$60-64$ & 7,464 & 2,596 & 2.1 & & 25,115 & 3,205 & 15.2 \\
$65-69$ & 7,051 & 2,556 & 2.3 & & 27,600 & 3,721 & 15.2 \\
$70-74$ & 7,470 & 2,913 & 2.5 & & 28,086 & 3,529 & 14.7 \\
$75-79$ & 7,371 & 3,004 & 2.5 & & 28,560 & 3,451 & 14.7 \\
$80-84$ & 7,147 & 2,959 & 2.7 & 25,119 & 3,121 & 15.4 \\
$85-$ & 7,814 & 2,898 & 2.5 & 22,872 & 2,574 & 16.4 \\
Average & 7,020 & 2,344 & 2.0 & 25,888 & 3,113 & 13.8 \\
\hline
\end{tabular}

dren was $22.5 \%$ lower than the average. For pediatric inpatient services, the daily revenue is higher than average, but the length of stay was only $50.2 \%$ of the average. Accordingly, revenues from providing inpatient services for children were lower than those for adults.
Number and rate of faculties providing pediatric care

From 1984 to 2002, the number of general hospitals ranged from 8,100 to 9,100 . From 1990, the increase in the number of general hospitals tended to decline. Over $80 \%$ of general hospitals provided internal medicine services, and about
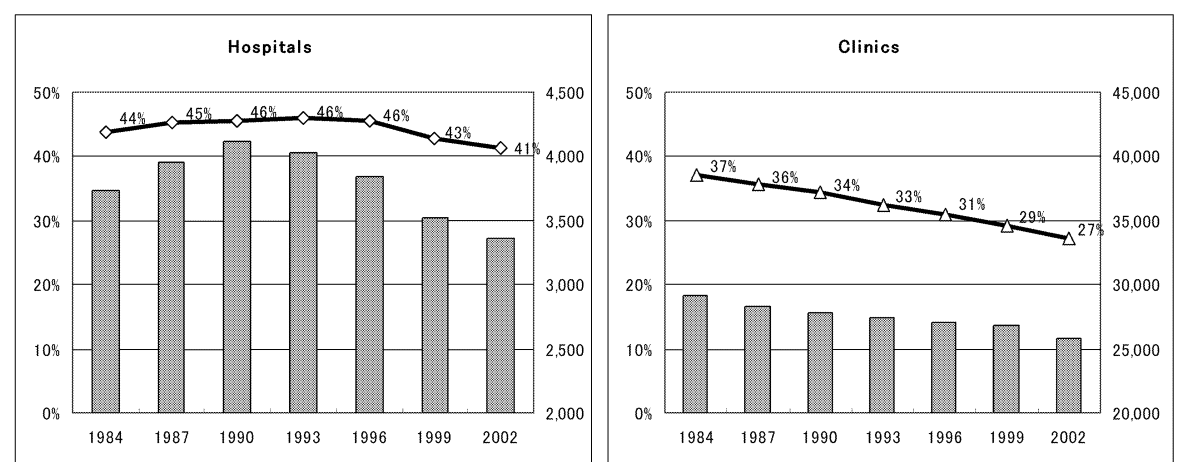

Fig. 4. Numbers and rates of facilities providing pediatric services. 
$70 \%$ provided surgical services. Only $46 \%$ of the general hospitals provided pediatric services. In contrast to the increasing number of general clinics, the percentages of clinics providing pediatric services had decreased greatly, from $37.2 \%$ in 1984 to $27.3 \%$ in 2002. Both the number and percentage of hospitals and clinics providing pediatric services had declined between 1990 and 2002 (Fig. 4).

\section{Discussion}

In this paper, by assembling data from several sources which were widely used by policy makers and researchers, we confirmed that the number of children had decreased greatly, and found for the first time that the number of pediatricians internist decreased accordingly with the number of children, while the number of pediatric specialists increased. However, the market share of medical services for children had declined 1.7 percent, and the PCPRs in large cities were greater than those in the other areas. Our results showed that over $80 \%$ of outpatient pediatric services were provided by clinics, over $95 \%$ of clinics were closed on holidays, Sunday, and Saturday night, and that the children's illnesses were predominantly those of the respiratory system, and generally acute and required immediate treatment or consultation. The results also showed that the revenue rates from providing services for children were lower than those for adults, and both the number and rate of hospitals and clinics providing pediatric services had declined recently.

It may be useful to summarize the main worries of parents concerning their children's access to pediatric services, a topic which has been addressed recently by the public media. These include three aspects, (1) where parents go to receive pediatric services for their children outside of normal working hours, (2) what to do about the decreasing pediatric service capacity during regular working hours in a society with decreasing number of children, and (3) how to ease the heavy burden of hospitals which provide or may be required to provide pediatric services.

Children's illnesses, when compared with those of adults, tend to be more often acute
(Tanaka et al. 2002). In some emergency centers at night, nearly half of the patients were children (Aichi Medical Association 2002). In spite of the higher requirement for pediatric services outside of normal working hours, over $95 \%$ of clinics were closed on Saturday night, Sunday and holidays, and only $21 \%$ of clinics were open on weekday nights. This may be the main reason why it is difficult to find pediatric services during such times.

Among others, we also found that the number of clinics and hospitals providing pediatric services continues to decline, and more physicians refuse to provide services for children. As for the reason more clinics and hospitals refuse to provide services for children in the daytime or at night, the lower revenue rates may be one of the key factors. As described above, outpatient revenue for pediatric service is lower, and re-consulting rate of children is also lower. For children of inpatient services, however, the daily revenue is slightly higher, but the average length of stay is shorter. The lower outpatient service revenue rate for children was partly because fewer drugs are prescribed and the period of prescription for children tends to be shorter. Unlike children, many adults required several kinds of drugs, and the administration periods for chronic diseases are often long (TV-ASAHI 2002). Combined with the lower profit margin, the treatment of pediatric diseases often requires more manpower. Besides, continually decreasing number of children (Kaneko et al. 2004) may be partly responsible for the decline in the number of pediatricians internist, because most of their patients were adults, and child patients accounted for only a small fraction. Such factors could be mainly responsible for the decreasing capacity of pediatric services.

The increasingly heavy burden of hospitals in providing pediatric services partially results from the high out-of-service rate of clinics during special time periods and the decrease in the number of institutes providing pediatric medical services. These two factors force patients to concentrate in fewer selected hospitals and clinics.

Many suggestions have been made to solve this problem. The Kumamoto model calls for all 
practicing pediatricians in local areas to provide pediatric services alternatively at night; the Morioka model has succeeded in dispersing patients to several hospitals, and the Kitakyushou model ensures that at least one hospital provides emergency services for children 24 hours a day, 365 days a year. The Tokushima Red Cross Hospital model also makes pediatric services available at night, but it is essential to increase the number of pediatricians (Tanaka 2004). In addition, some have suggested providing suitable conditions for attracting more female pediatric specialists to return to work after giving birth to their own children (Tanaka 2003).

Two misconceptions have been harmful. One is that the accessibility to pediatric services, including emergency and after hour services, is only the responsibility of pediatric specialists. However, one survey showed that over $70 \%$ of internists and pediatricians thought that primary emergency care for children should be provided by pediatric specialists (Tanaka 2000). We do not know exactly whether it is this belief that gave many physicians a cause to refuse to provide services for children. Even though the number of pediatric specialists has increased, pediatricians internist represent an important compensating asset. The other misconception is the belief that pediatricians internist can not provide high quality service for children. In fact, most children's illnesses are not serious (Ichikawa 2000), and most pediatricians internist can deal with them well at day time.

The above results and analysis confirmed the appropriateness of the proposals by the Japanese Pediatric Society (2005) for improving the present status of pediatric services, and provided additional national-wide concrete evidence from multiple dimensions for policy makers.

This study had several limitations. Most of our data were secondary. Some data, such as total and precise time of out-of-working hour consultant services, are unavailable. In addition, this research had not thoroughly clarify the relationship among the decreasing number of children and pediatricians internist, the increasing number of pediatric specialists, the decreasing number and rate of facilities providing pediatric services, and lower open rates of clinics in out-of-working time.

\section{Conclusion and Suggestion}

Clinics provide most medical services for children. However, few are open on Saturday night, Sunday and holidays, and weekday nights. This may be the main reason why it is difficult to find pediatric services during out-of-service hours. Lower revenue rates may be one of the key reasons that the number of clinics and hospitals providing pediatric services continues to decline, and more physicians refuse to provide services for children. The heavy burden on some hospitals in providing pediatric services partially results from the lack of open clinics during out-of-service hours and the decreasing number of institutes providing pediatric medical services.

Our proposition is, (1) to require pediatric specialists and pediatricians internist in working clinics to provide pediatric service systematically and alternatively at night in order to security service capacity, and (2) to adjust the fee-for-service scales and make the profit margin of treatment for children comparable with that for adults, in order to encourage more pediatricians internist willing to provide services for children. Questions such as how to adjust the fee rates and in what degree are worthy of further researching.

Such problems in the provision of pediatric services may be related to the Japanese health system, which is characterized by unregulated practice for physicians, free-access for patients, and fee-for-service of payment. The greatly decreased availability of pediatric services at night reflects both distortions in the pricing of services and a market failure in health service industry. It is time for the government to address this issue seriously.

\section{References}

Aichi Medical Association (2002) Report of Committee of emergency medicine.

Anonymous (2001a) To improve emergency pediatric services. Asahi Shimbun, December 15, (Morning edition), 27.

Anonymous (2001b) It is necessary to allocate suitable physicians for pediatric emergency care. Asahi Shimbun, July 16, (Morning edition), 2.

Anonymous (2001c) The suicide of a pediatrician, survivors' 
application for compensation, Tokyo Kosei Hospital. Asahi Shimbun, September 18, (Morning edition), 37.

Anonymous (2001d) Children's emergency visit. Asahi Shimbun, September 20, (Morning edition), 22.

Ichikawa, K. (2000) Evaluation of the severity of children emergency service from the view points of pediatricians. Mahoroba, 87-96.

Kaneko, M., Ali, M. \& Ushijima, H. (2004) Relationship between decreasing fertility during the post-war period and maternal age in a Japanese population. Tohoku J. Exp. Med., 202, 221-226.

National Institute of Population and Social Security Research (2002) Population trend, Japan and the World. Health and Welfare Statistics Association, Tokyo, 181.

Randolph, G.D. \& Pathman, D.E. (2001) Trends in the ruralurban distribution of general pediatricians. Pediatrics, 107, E18.

Statistics and information department, Minister's secretariat, Ministry of Health, Labour and Welfare (2002a) Survey on physician, dentist, and pharmacist. Health and Welfare Statistics Association, Tokyo, 119-122.

Statistics and information department, Minister's secretariat, Ministry of Health, Labour and Welfare (2002b) National medical expenditure. Health and Welfare Statistics Association, Tokyo, 42-49.

Statistics and information department, Minister's secretariat, Ministry of Health, Labour and Welfare (2002c) Patient
Survey 2002 Volume I. Health and Welfare Statistics Association, Tokyo, 26-48.

Statistics and information department, Minister's secretariat, Ministry of Health, Labour and Welfare (2002d) Reimbursement Survey for Social Health Services. Health and Welfare Statistics Association, Tokyo, 18-36.

Statistics and information department, Minister's secretariat, Ministry of Health, Labour and Welfare (2002e) Medical Facility Survey. Health and Welfare Statistics Association, Tokyo, 30-43.

Tanaka, T. (2000) Study on who should provide primary emergency care for children. Mahoroba, 69-84.

Tanaka, T. (2003) Pediatric emergency services and the working environment for female physicians. Pediatr. Int., 170, $1478-1485$.

Tanaka, T. (2004) The present and future of emergency medicine for children. Diagnosis and Treatment Press, Tokyo, 130-135.

Tanaka, T., Ichikawa, K. \& Yamada, S. (2002) The status quo of Japan emergency medical service system for children from the second medical circle levels. Japan Medical Journal, 4071, 59-62.

The Japanese Pediatric Society (2005) http://jpsmodel.umin.jp/ ACTIONPLAN20050219.htm, accessed on March 23, 2005.

TV-ASAHI (2002) http://www.tv-asahi.co.jp/ss/47/crinic/top. html, accessed on February 3, 2005. 